\title{
ISLAM DI AFRIKA UTARA
}

\author{
Vita Ery Oktaviyani* \\ Program Studi Sejarah Kebudayaan Islam, Program Pascasarjana UIN Sunan Kalijaga, Indonesia
}

\begin{abstract}
This article discusses the history of Islam of North Africa and the existence of Muslims of North Africa. When the era of the glory of Islam in Spain ended, the Muslim community in North Africa entered a new stage of development. The development of Islam of North Africa influences the development of politics, governance, economy, social, culture, science, technology, then architecture, and the development of the civilization of Islam of North Africa rather than its relationship with Andalusia.
\end{abstract}

Keywords: Islam, North Africa, Islamic civilization.

\section{Abstrak}

Artikel ini membahas mengenai sejarah Islam di Afrika Utara dan bagaimana keberadaan umat muslim di Afrika Utara. Saat era kejayaan Islam di Spanyol berakhir, masyarakat muslim di Afrika Utara justru memasuki tahap perkembangan baru. Perkembangan Islam di Afrika Utara mempengaruhi perkembangan politik dan pemerintahan, ekonomi, sosial, budaya, ilmu pengetahuan, teknologi, dan arsitektur, serta perkembangan peradaban Islam di Afrika Utara dan hubungannya dengan Andalusia.

Kata Kunci: Islam, Afrika Utara, Peradaban Islam.

\section{PENDAHULUAN}

Dalam terminologi Arab, daerah-daerah yang termasuk bagian Afrika Utara meliputi: lembah sungai Nil bagian bawah yang disebut dengan al-Misr (Mesir modern), Libya, Cyenacia, Tripolitania dan Tunisia, yang seluruh wilayah itu dikenal orang-orang Arab sebagai Afrika; serta wilayah Aljazair dan Maroko, yang oleh orang-orang Arab dikenal dengan sebutan al-Maghribi (Maryam, 2012, pp. 219-220). Kehidupan sosial masa lalu Afrika Utara adalah masyarakat pedesaan yang bersifat kesukuan, nomad (berpindahpindah tempat) dan patriarkhi. Menurut Ira M. Lapidus, yang termasuk wilayah Afrika Utara adalah Aljazair, Tunisia, Maroko dan Libya (Maryam, 2012, p. 237).

Afrika Utara merupakan daerah penting bagi penyebaran agama Islam di daratan Eropa, meskipun begitu kekuasaan Islam tidak berjalan mulus. Ketika pertama kali Islam masuk daerah ini, guncangan politik akibat pemberontakan orang Barbar dan Romawi muncul silih berganti. Saat pasukan Kristen ingin kembali menguasai Andalusia, para pengungsi berdarah Arab yang dikenal Maghribi Barbar bermigrasi menuju Afrika Utara. Mereka membentuk perkampungan Andalusia di Tunisia. Sebagian masyarakat petani Spanyol memperkenalkan irigasi, penggilingan, perkebunan dan kebun anggur. Kaum migran diberi hak otonomi dalam mengumpulkan pajak, membentuk juru bicara yakni Syaikh Al-Andalus.

Kemajuan Afrika Utara dalam bidang arsitektur, dekorasi, seni bangunan masih bisa dinikmati hingga sekarang. Dalam bidang intelektual nama Ibn Battuta, Ibn Khaldun, Ibn Zuhr, Ibn Rusyd, Ibn Tufayl telah menjadi simbol kemajuan peradaban Islam di daerah tersebut.

\section{HASIL DAN PEMBAHASAN}

\section{Sejarah Islam di Afrika Utara}


Sejak periode awal Islam hingga abad ke-19, sejarah masyarakat Afrika Utara berlangsung dalam dua motif utama yaitu pembentukan negara dan Islamisasi. Penaklukan bangsa Arab terhadap masyarakat Barbar bermula dari dikuasainya Mesir, Tunisia pada abad ke-8, Maroko abad ke-11 dan Aljazair abad ke-16. Masyarakat Barbar terbagi menjadi dua yaitu Barbar pemukiman yang awalnya bertahan sebagai penganut Kristen, dan Barbar nomadic yang mendaftarkan diri sebagai pasukan bersenjata Arab dan membantu warga menyebarkan Islam ke Aljazair, Maroko dan Spanyol. Penaklukan oleh bangsa Arab mendorong pembentukan komunitas muslim. Peradaban Arab-Islam di Afrika Utara dibentuk berdasarkan integrasi kalangan penakhluk Arab dengan masyarakat Barbar dan kota-kota di wilayah Laut Tengah. Beberapa kota di Afrika Utara merupakan pelopor peradaban Bizantium Romawi dan Bizantium Punic (Lapidus, 200o, pp. 562-563).

Hingga pertengahan abad ke-13, sejarah wilayah ini sejalan dengan periode kekhalifahan dalam sejarah perkembangan Timur Tengah dan merupakan tipe peradaban Islam Timur Tengah. Pada abad ke-16, sebagian besar wilayah Afrika Utara (kecuali Maroko) jatuh ke tangan Dinasti Usmani. Pada abad ke-18 dan ke-19, beberapa masyarakat dihancurkan oleh kompetisi ekonomi bangsa Eropa dan akhirnya jatuh ke dalam kekuasaan pemerintah kolonial.

Mulai abad delapan mahzab Maliki berkembang pesat di seluruh penjuru Afrika Utara sebagai administrasi hukum, pendidikan dan legitimasi. Dua abad kemudian Sufisme juga menjadi basis pengorganisasian warga pedalaman di Tunisia, Aljazair dan Maroko. Ia menjadi pemimpin koalisi kesukuan sebagai perlawanan bagi rezim negara (Lapidus, 2000, pp. 629-630).

Saat keberadaan umat muslim di Spanyol berakhir, masyarakat muslim di Afrika Utara justru memasuki tahap perkembangan baru. Dengan kehancuran Dinasti AlMuwahhidun mulai terbentuk konfigurasi baru antara negara dan masyarakat. Meskipun pola kekhalifahan tetap dilanjutkan namun negara-negara Afrika Utara mengarah pada pola struktur institusional Timur Tengah model Saljuk dan model Mamluk-Ayyubiyah di Mesir. Beberapa rezim dibentuk mewarisi Dinasti AlMuwahhidun dimana mereka didukung mawali (golongan muslim non-Arab), pasukan budak, pasukan bayaran dan birokrasi keluarga yang bergantung pada kesukuan yang berkuasa. Sejalan dengan hal tersebut terjadi penyebaran Sufisme.

\section{Perkembangan Peradaban Islam di Afrika Utara}

\section{Politik dan Pemerintahan}

Dinasti Al-Murawiyyah atau Al-Murabithun (448-541 H/1056-1147 M) terdapat di Afrika Utara dan Spanyol. Ia telah memprakarsai peradaban Islam di Afrika Utara. Ia menyokong kemenangan Islam Sunni dan mahzab Maliki dalam persaingan dengan Syi ' i dan Khariji. Awal abad ke-11 pemimpin Sanhaja, Yahya ibn Ibrahim dari Mekkah mengundang Abdullah ibn Yasin, seorang alim Maroko untuk berkarya di tengah kaumnya. Dibangunlah ribat (benteng) di mulut Sungai Sinegal, dari sini prajurit iman menyebarkan Islam melalui Sudan barat. Prajurit itu terkenal sebagai Murabithun (orang yang tinggal di benteng tapal batas). Orang Barbar gurun ini mengenakan cadar di wajah mereka, sehingga dikenal sebagai Al-Mutalatstsimun (orang-orang yang 
bercadar). Al-Murabithun didirikan oleh Abdullah ibn Yasin, seorang tokoh agama dari Qairawan. Pada mulanya sebagai gerakan keagamaan. Setelah berhasil memasukkan pengaruh ke suku Sanhaja, Abdullah ibn Yasin mengajarkan agama dan membimbing ibadah. Selain itu juga menghimpun dan melatih jihad melawan orang kafir. Selanjutnya suku-suku lain juga berhasil ditaklukkan diantaranya: Judalah, Missufah, Lamtunah, Mahmunah dan Tikalatah. Kemudian pergerakan diarahkan menjadi pergerakan politik dan kemiliteran. Urusan politik dan administrasi keuangan dipegang oleh Abdullah ibn Nasir, sedangkan kemiliteran dipegang Yahya ibn Umar. Yahya ibn Umar berhasil meluaskan kekuasaan hingga Wadi Dar'ia dan Sijilmasat (448 H/1055 M). Sepeninggal Yahya ibn Umar, urusan dipegang Abu Bakar ibn Umar yang dilanjutkan Yusuf ibn Tasyfin (Bosworth, 1993, p. 50; Maryam, 2012, p. 227).

Sejak saat itu atas dasar keagamaan para pendahulu, Al-Murabithun berdiri sebagai dinasti dengan Yusuf ibn Tasyfin sebagai raja pertama. Kekuasaan berlangsung mulai 480-541 H/1088-1147 M. Kemudian dilanjutkan oleh Ali ibn Yusuf, Tasyfin ibn Ali, Ibrahim ibn Tasyfin dan Ishak ibn Ali. Menjelang pertengahan abad ke-12 kekuasaannya mulai retak. Kehancurannya disebabkan oleh beberapa hal antara lain: korupsi dan lemahnya tentara, terlena dengan kehidupan mewah, dan dikalahkan oleh dinasti lain (Sunanto, 2005, pp. 135-136).

Al-Muwahhidun merupakan dinasti Islam yang pernah berjaya di Afrika Utara memerintah dari 515-667 H/1121-1269 M. Didirikan oleh Muhammad ibn Tumart (1080$1130 \mathrm{M}$ ), yang lebih dikenal dengan sebutan Ibn Tumart pada tahun 1114 M (Islam, 1993, p. 319). Al-Muhad dari Al-Muwahhidun artinya orang-orang yang mengesakan Allah, secara intelektual mewakili protes terhadap mahzab Maliki yang kaku, konservatif dan legalistik sebuah mahzab yang dominan di Afrika Utara (Bosworth, 1993, p. 52). Pada tahun 1117 M gerakan keagamaan ini berubah menjadi gerakan politik dan para pengikut menyebut Ibn Tumart sebagai Imam Mahdi. Gerakan ini makin sukses dengan Abdul Mu'min sebagai ahli strategi dan militer. Sepeninggal Ibn Tumart, Abdul Mu'min bergelar khalifah dan berhasil menakhlukkan Dinasti Al-Murabithun serta menguasai seluruh wilayah Magribi. Selanjutnya ia memindahkan pusat pemerintahan AlMuwahhidun di Tinmallal ke Marrakesh. Dinasti Al-Muwahhidun mengakibatkan berakhirnya warga Kristen di Afrika Utara, jumlah Yahudi juga berkurang. Perhatian utama ditujukan untuk mempertahankan Islam agar jangan sampai jatuh ke tangan Nasrani (Amarullah, 1975, p. 157).

Di bawah pimpinan Abdul Mu'min kemajuan peradaban Islam di Afrika Utara mencapai puncaknya. Meski kemajuan merupakan kelanjutan masa sebelumnya, namun tetap memiliki sisi menarik dan menonjol. Struktur negara mencerminkan watak mesianis dan otoriter ajaran Ibn Tumart, dan dibangun dengan hierarki ketat para penasihat dan orang dekat khalifah. Kekuasaan dinasti ini hingga Aljazair, Tunisia, Tripoli (Libya). Di bawah pimpinan putranya Abu Ya'kub Yusuf ibn Mu'min ibn Ali (580 H/1184 M) Al-Muwahhidun berhasil menguasai Andalusia yang dikuasai orang Kristen. Penggantinya Abu Yusuf Ya'kub Al-Mansur, pada awal pemerintahannya terjadi dua pemberontakan di Spanyol, pertama oleh penguasa Kepulauan Miurqah, Manurqah dan Yabisah, kedua orang Kristen yang berusaha merebut wilayah Islam di Spanyol. Tahun $591 \mathrm{H} / 1194$ M Raja Alfonso kembali memberontak, namun pemberontakan demi pemberontakan berhasil digagalkan. 
Kemenangan Al-Muwahhidun ini merupakan kemenangan terakhir muslim terhadap Kristen di Spanyol. Di beberapa wilayah Maghribi terjadi pemberontakan yang ingin melepaskan diri dari Al-Muwahhidun. Pemberontakan besar dilakukan oleh Ali ibn Ishaq, bersamaan dengan pasukan Al-Muwahhidun berperang dengan pasukan Kristen di Spanyol. Kekuasaan dinasti ini tidak mampu menahan gerak orang-orang Kristen, koalisi raja-raja Kristen menyebabkan dinasti ini menarik diri dari Spanyol. Penyebab runtuhnya Dinasti Al-Muwahhiddun di Andalusia karena pemerintahan tidak dijalankan oleh pemimpin dan tidak membuat ibukota (Al-Ilm, 2013, p. 141). Sultansultan hanya berkuasa di Afrika Utara, dan perlahan berkurang. Akhir masa kekuasaan ditandai dengan kemunculan Yaghamrasan bin Zayyan di Tlemcen (Tilimsan) tahun 633 H / 1236 M yang mendirikan Dinasti Abdul Wadiyah.

Sejak akhir abad ke-13 sejumlah zawiya sufi mulai menjalankan fungsi sosial dan politik. Ia mengorganisir kesukuan untuk mengamankan rute perdagangan, menumpas perampok, menyebarkan agama, serta menentang pemungutan pajak ilegal. Pada abad ke-14 Sufisme terkonsolisasi lantaran pejabat politik cenderung mencari dukungan. Pada tahun 1399 zawiya-madrasah yang didirikan melambangkan integrasi antara Sufisme perkotaan dan Islam Maliki.

Penduduk Aljazair terdiri dari orang Barbar dan Arab. Hampir semua penduduknya Islam dan menggunakan bahasa resmi Arab di samping Perancis dialek Barbar. Ada empat periode penting berkaitan pengembangan Islam di Aljazair yaitu: (1) masuknya agama Islam (Tahun $682 \mathrm{H}$, zaman Dinasti Umayyah); (2) Maraboutism (Pemujaan orang-orang yang disebut marabout, yang dianggap oleh penduduk memiliki kesucian, kebijaksanaan dan hubungan dekat dengan Allah serta mempunyai kekuasaan untuk campur tangan secara positif dalam situasi kecemasan dan ketegangan); (3) Islam dan perlawanannya terhadap kolonial; dan (4) Islam dalam Aljazair modern (Islam, 1993, p. 122). Aljazair memiliki perjalanan sejarah yang berbeda, ia sebuah negara yang tidak memiliki organisasi negara. Selanjutnya Aljazair jatuh ke dalam periode sejarah Islam, meskipun tetap mendukung organisasi lokal seperti Dinasti Hammadiyah dan Zayyaniyah. Namun, beberapa rezim ini tidak pernah menguasai Aljazair, sehingga membuka peluang munculnya oposisi kesukuan. Sebuah rezim yang kuat akhirnya terbentuk melalui penakhlukan Dinasti Usmani (1529 M), didukung pasukan Jennisery. Otoritas Turki-Usmani telah diterima di seluruh Aljazair meskipun tidak seragam. Bahkan perlawanan propinsial kesukuan dan dari kalangan Sufi muncul pada abad ke-18. Rezim Aljazair-Usmani berhasil membentuk identitas territorial dan identitas pemerintahan Aljazair. Tidak lama kemudian otoritas gubernur yang diangkat Dinasti Usmani tersingkir oleh agha (pejabat tinggi Jennisery) dan ra 'is (kapten pasukan laut). Pada tahun 1659 Agha Jennisery menjadi penguasa Aljazair, kepala negara bergelar Dey. Sejak 1689-1830 M Aljazair diperintah kalangan Dey dan elite militer Jennisery Turki. Meskipun upeti tetap dikirim ke Istanbul sebagai imbalan dukungan politik, namun secara esensial Aljazair telah menjadi negara merdeka.

Maroko menjelang penaklukan Arab tidak memiliki sejarah territorial dan rezim yang memusat. Maroko mempunyai peran besar dalam sejarah menyebarkan Islam di Afrika Utara dan sebagai pintu gerbang masuknya Islam ke Spanyol dan Eropa. Pada awalnya Maroko dikuasai dinasti Idrisiyah, selanjutnya dikuasai oleh Al-Murabithun yang beribukota di Marrakus. Kekuasaannya hingga Gurun Sahara, Afrika Barat Laut 
dan Spanyol (Islam, 1993, p. 166). Sejak penaklukan Al-Murabithun mengawali proses pembentukan basis teritorial bagi Maroko. Kemudian secara berturut-turut pemerintahan Al-Murabhitun diganti oleh Al-Muwahhidun, Mariyah, Sa'dian dan Alawis. Pada abad ke-17 dan ke-18 upaya pemerintah untuk mengendalikan koalisi kesukuan dan koalisi Sufi, terhalangi oleh konflik antar elite. Kepemimpinan kesukuan di Maroko tidak mampu bertahan lama, karena sering terjadi perebutan kekuasaan. Koalisi sufi juga tidak stabil sebab bersifat personal bukan organisasional dan bergantung pada pemihakan suku. Dalam organisasi sosial masyarakat pedalaman bergantung pada sarana simbolik dan ritual. Lemahnya negara menyulitkan pengumpulan pajak, Sultan mencoba melakukan perdagangan namun hanya dinikmati sendiri (Lapidus, 200o, p. 635). Pada tahun 1856 Maroko dipaksa Inggris menyetujui perjanjian untuk membuka perdagangan bebas dengan komisi 10\%.

Masyarakat Tunisia dari abad ke-13 hingga ke-19 merupakan rekonstruksi terhadap bentuk pemerintahan memusat di masa lampau yang didasarkan pada perekonomian perkotaan dan kuatnya kekuasaan terhadap warga pedalaman. Dinasti Hafshiyyah berasal dari nama Syaikh Abu Hafsh Umar, murid Ibn Tumart. Dinasti ini berkuasa 625-982 H/1228-1574 M didirikan oleh Abu Zakaria Yahya, seorang gubernur Ifriqiyah. Ia menolak kekuasaan khalifah Al-Muwahhidun tepatnya saat pemerintahan Abdul Wahid dengan perbuatan bid'ah (Bosworth, 1993, p. 59). Ia berekspansi ke Maghribi Tengah, memaksa dinasti Abdul Wadiyyah membayar pajak serta memaksa dinasti Mariniyyah menerimanya serta bersedia membantu muslimin di Spanyol Selatan yang terkepung. Kekuasaan Dinasti Hafshiyyah besar di bawah kepemimpinan Al-Muntashir, ia menggambarkan diri sebagai penguasa muslim dengan menggunakan gelar khalifah dan amir al-mukminin.

Sepeninggal Al-Muntashir Dinasti Hafshiyyah mengalami goncangan hebat, banyak terjadi perebutan kekuasaan, kekerasan bajak laut. Akibatnya Kaisar Charles V, menempatkan tentara Spanyol di Tunisia tahun 941 H/1535 M. Beberapa saat Dinasti Hafshiyyah mampu mempertahankan diri dari serangan Turki, namun tahun 981 H/1574 M Sinan Pasha berhasil menaklukkannya dan penguasanya dibawa ke Istambul. Sejak jatuhnya Dinasti Hafshiyyah yang berkuasa di Tunisia adalah Kerajaan Turki Usmani. Kerajaan itu mengirimkan wakil-wakilnya untuk memerintah disana. Pada tahun 1117 H/1705 M, rakyat Tunisia meminta agar Husain ibn Ali Basya diangkat sebagai raja dengan gelar Pasya. Keturunannya juga diangkat sebagai raja dengan otonomi penuh. Sementara Perancis selalu berusaha menakhlukkan daerah tersebut. Tahun 1881 Muhammad Sadiq Baai menandatangani perjanjian dengan Jenderal Beriar, dan Tunisia masuk ke dalam kekuasaan Perancis.

\section{Ekonomi}

Migrasi muslim Andalusia membuat para pujangga, penulis, ilmuan dan tentara mendapat dukungan rezim Hafshiyyah. Sebagian mereka memasuki dinas militer Tunisia. Pada abad ketujuhbelas tekanan Kristen terhadap muslim Spanyol makin tinggi menyebabkan pesatnya arus migrasi dan puncaknya peristiwa pengusiran Moriscos (sebutan bagi muslim Spanyol). Mereka membentuk perkampungan Andalusia di Tunisia. Kaum migran diberi hak otonomi dalam mengumpulkan pajak, membentuk juru bicara yakni Syaikh Al-Andalus. 
Beberapa wilayah Afrika Utara berhasil mempertahankan laju perekonomian. Wilayah pedesaan menghasilkan buah zaitun, anggur dan biji-bijian, sedangkan wilayah perkotaan industri tekstil dan keramik. Perdagangan dengan Eropa, Mesir dan sub-Sahara Afrika sangat penting. Bahkan produk utama arus perdagangan Afrika Utara dengan Sudan adalah budak dan emas. Aljazair kaya minyak bumi antara lain ada di Hassi R’mel, Hassi Messaoud, Edjeleh dan Berga.

Migrasi muslim Andalusia ke Afrika Utara memperkuat sektor pemukiman dan perdagangan. Akibat migrasi petani Andalusia memperkenalkan irigasi, penggilingan, perkebunan dan kebun anggur. Hingga akhir abad ke-18 perekonomian masyarakat Tunisia dijalankan dalam cara tradisional. Ia mampu mengeksport daging, wool, minyak zaitun, kulit jangat, lilin, kurma dan roti. Sedangkan Tunisia mengimpor pakaian dan kertas. Alin (1759-1782 M) dan Hammuda Pasha (1782-1813 M) melengkapi kebijakan untuk memaksimalkan perniagaan. Mereka memanfaatkan perdagangan dengan Eropa, untuk memperluas perdagangan. Industri picis bulu, yang dikenalkan oleh muslim Andalusia menjadi industri yang besar. Shashiya merupakan picis standar yang dikenalkan di wilayah Laut Tengah oleh umat Kristen, Yahudi dan Muslim. Produksi picis bergantung pada perdagangan internasional, wool didatangkan dari Spanyol. Produksi picis di Tunisia mencapai 100.000 lusin setiap tahun. Ketika Tunisia dilanda situasi tidak mendukung, seperti aturan yang ditetapkan Bey Tunis, penguasaan bangsa Eropa terhadap bahan mentah, organisasi kerjasama yang ketat dan biaya produksi tinggi namun mereka tetap memiliki kelebihan dalam memahami situasi pasar dan pembuatan produk yang berkualitas. Namun, akhir abad delapanbelas perekonomian Tunisia mengalami kemunduran. Sejak 1784-1820 M terjadi kegagalan panen, wabah penyakit akibatnya produksi minyak zaitun diganti gandum. Pada saat yang sama Eropa mengalihkan perdagangan ke Laut Tengah. Shashiya tidak mendapat pasar, karena harus bersaing dengan produk Perancis. Revolusi Industri di Eropa makin memperburuk kemerosotan ekonomi di Tunisia, akibatnya ia bergantung pada Eropa. Tahun 1869 Tunisia dipaksa tunduk kepada komisi Perancis, Inggris dan Italia untuk mengumpulkan pajak dan melunasi hutang.

Sebelumnya pada awal abad ke-15 perekonomian Maroko dihancurkan Portugis, ia merebut pesisir Maroko. Portugis bergerak ke sepanjang wilayah pesisir Afrika untuk membuka hubungan dagang dengan Afrika Sudan. Sejak penakhlukan Sudan 1591 M hingga abad ke-19 Maroko diuntungkan melalui kekuasaan terhadap perdagangan Sudan dan Sahara. Abad ke-18 ia mampu mengimpor budak, sebagai imbangan ekspor pakaian, sutera, permata, baja, kulit jangat dan senjata. Dari bangsa Eropa Maroko mengimpor teh, kopi, gula, kertas, timah, tembaga, perabotan rumah tangga dan rempah-rempah dari India. Inggris dan perancis merupakan patner utama perdagangan Maroko. Maroko mengalami kemunduran sejak dibukanya Terusan Suez (1869 M) dan pembukaan jalur kapal dan kereta api. Hal ini menyebabkan produsen Amerika, Rusia dan Australia mensuplai gandum dan wool untuk bersaing dengan produk Maroko.

\section{Sosial, Budaya, dan Agama}

Awalnya Qairawan dan Tunisia merupakan pusat pengajaran mahzab Maliki. Pada abad ke-12 Abu Madyan Al-Andalusi membawa bentuk Sufisme Spanyol ke Afrika Utara. Selanjutnya Sufisme memperkuat posisi di Afrika Utara. Ulama Sufi menyebar ke 
Tunisia, Bone, Qairawan, dan memiliki cabang di Maroko yakni kota Aghmat, Marrakesh. Ia mampu mengantarkan muslim menjadi organisasi sosial yang sangat berpengaruh bagi masyarakat pedalaman. Semua rezim mengakui ulama dan sufi sebagai pemangku legitimasi Islam dan perantara dalam menjalankan pemerintahan atas warganya. Kekuatan negara berhadapan dengan kesukuan dan kekuatan politik yang bergantung pada jalur dagang yang menghubungkan Afrika Utara, Sahara, Sudan dan Eropa. Semuanya bergantung dari perdagangan Eropa, bahkan dukungan militer. Kepemimpinan sufi mampu menyatukan warga pedalaman yang mendukung tatanan politik, pertahanan, organisasi ekonomi, penengah perselisihan dan fungsi penting lainnya. Pertumbuhan pesat komunitas muslim di penjuru Afrika Utara berhasil menghubungkan kepada dunia Arab dan dunia Islam Timur Tengah.

Di Aljazair beberapa guru sufi mengumpulkan pengikut, mereka memilki tanah luas dari hadiah penguasa lokal yang mereka angkat. Para sufi menjadi tuan tanah, ahli ilmu dan pembimbing spiritual sebagian petani kecil. Sejak saat itu struktur politik Aljazair didasarkan kesukuan atau keturunan, komunitas pimpinan sufi dan beberapa rezim negara. Sementara penyebaran sufisme di pedalaman memberikan Aljazair identitas Islam.

Penguasa Sa'dian dan Alawis di Maroko dipandang sebagai khalifah. Sultan sekaligus sebagai khalifah, imam, syarif, wali dan mujtahid mempunyai peran ritual khusus dalam hari-hari besar muslim, ia sangat dimuliakan sebagaimana layaknya tokoh agama. Sultan-sultan Maroko tidak memonopoli legitimasi religius, namun legitimasi sebagai keturunan syarifian dan barakah sufi dimiliki bersama dengan tokoh agama. Kebersamaan ini adakalanya bersifat suportif maupun kompetitif. Sifat kepribadian yang tinggi di kalangan kerajaan memperkuat legitimasi sekaligus sumber kelemahan. Kekuasaan di dukung hubungan personal penguasa dengan klien. Maroko mengembangkan identitas territorial dan monarki yang khas, dibangun berdasar otoritas keagamaan sultan yang bersifat pribadi. Sejak abad ke-16 sampai ke-18 pemerintah pusat melemah, menimbulkan ekspansi kelompok pastoral. Ulama hanya sebagai strata yang lemah, bergantung pada Sultan berusaha mempertahankan perkotaan tanpa sandaran politik. Mereka juga harus bersaing dengan sultan, wali dan thariqat sufi untuk meraih prestise keagamaan. Akibatnya memunculkan kelompok kesukuan dan kelompok sufi.

Kemunduran ekonomi dan politik di Maroko dalam periode Mariniyyah dan Waththasiyyah mengantarkan kebangkitan sufisme. Para sufi Maroko umumnya dari kalangan ulama hidup di tengah komunitas pedesaan. Tipe khas sufi abad ke-14 di Maroko mengkombinasikan antara pengetahuan mistisisme dan hukum, antara keilmuan literal dan praktik esoterik. Citra bangsa Maroko saat itu menyempurnakan sufi sebagai lambang bagi kualitas keagamaan nabi. Pada abad ke-15 negara Maroko mengalami kehancuran dan diduduki oleh Portugis. Hal ini menyadarkan masyarakat Maroko. Selanjutnya sufisme merupakan bagian penting dalam mengorganisir perjuangan lokal dalam memobilisasi perlawanan rakyat terhadap pendudukan Portugis. Kaum sufi memimpin koalisi kesukuan lokal, bahkan hingga melalui pemasyarakatan thariqat (Lapidus, 2000, pp. 618-619). Abad limabelas dan enambelas rezim negara Maroko bubar, untuk sementara sufi yang dominan, bahkan akhir abad enambelas rezim Maroko ditumbankan oleh Sa'dian. Sa'dian memimpin Maroko 
dengan tipe lain, ia mengikat diri pada kaum sufi dengan memindahkan jenazah AlJazuli ke Marrakesh untuk melambangkan pembentukan koalisi sejumlah thariqat sufi di sekitar makam yang dikeramatkan tersebut, sekaligus menjadikan hari kelahiran Nabi Muhammad SAW sebagai peringatan keagamaan bangsa Maroko yang terbesar (Lapidus, 2000, p. 621).

Abad ke-14 sufisme di Tunisia terkonsolidasikan secara memadai karena pejabat politik cenderung mencari dukungan, melambangkan sufisme perkotaan dan Islam Maliki. Secara bertaham sufisme menjadi basis bagi organisasi sosial masyarakat, yang menyebabkan kebancuran rezim Hafshiyyah.

\section{Ilmu Pengetahuan, Teknologi, dan Arsitektur}

Marrakesh merupakan pusat peradaban Islam, istana sebagai pusat seni dan ilmu bagi perkembangan Islam. Diantara penguasa Al-Muwahhidun, Abu Ya 'kub Yusuf yang paling dekat dengan ulama dan cendekiawan. Pada masanya hidup orang-orang besar seperti Ibn Rusyd (filsuf Islam yang mengilhami kebangkitan intelektual Barat), Ibn Tufayl (filsuf Islam pengarang buku Hayy ibn Yaqzan), Ibn Mulkun Abu Ishaq Ibrahim ibn Abdul Malik (ahli bahasa), Abu Bakar ibn Zuhr (ahli kesehatan dan menteri). Bahkan Ibn Thufayl dan Ibn Rusyd menjadi dokter istana. Ibnu Batuta merupakan ilmuan asli Afrika Utara. Tanggal 14 Juni 1325 (2 Rajab 725 A.H), ia meninggalkan Tangier untuk pengembara. Ia merupakan orang yang banyak pengalaman dalam pengembaraannya, namun di negaranya kurang menaruh perhatian pada bidang militer (Bosworth, 1993, p. 53; Dunn, 2013, pp. 23-24; Islam, 1993, p. 321).

Istana Hafsid di Tunisia menyelenggarakan berbagai studi Al-Qur'an, hadits, hukum, tata bahasa Arab, biografi Nabi Muhammad SAW dan para wali, kitab logat ulama-ulama besar, sejarah dan karya teologi. Gaya arsitektural periode ini berasal dari Maroko dan Mesir, namun sains dan ilmu kedokteran kurang berkembang (Lapidus, 2000, pp. 603-605).

Ulama-ulama Maliki merupakan pelajar tata bahasa, teologi, matematkia, astronomi dan kedokteran. Ibn Al-Tabban adalah pelajar hukum, filologi, tata bahasa, matematika, astronomi, kedokteran dan penafsir mimpi. Al-Qabisi adalah seorang teolog yang memusatkan perhatian pada hadits dan mistisime. Banyak dibangun masjid dan lembaga pendidikan tinggi, misalnya Masjid Zaituna dan Masjid Qairawan.

Tahun 1880-1930 M pemimpin Tunisia baik ulama maupun birokrat menerima kekuasaan Perancis di Tunisia dan berkonsentrasi pada bidang pendidikan dan budaya. Tahun 1888 alumni Zaituna dan College Sadiqi mengeluarkan serat kabar mingguan alHadira, sebagai media untuk mengomentari Eropa dan peristiwa dunia serta mendiskusikan isu politik, ekonomi dan sastra. Tahun 1896 para alumni mendirikan sekolah Khalduniyyah untuk menyuplai pendidikan Zaituna dengan unsur modern. Hasil dua lembaga ini adalah pemuda Tunisia yang berenergikan Arab Timur. Mereka mempromosikan modernisasi dan westernisasi masyarakat Tunisia dan kebangkitan Arab. Kelompok pemuda ini mensponsori reformasi, hukum Islam, pendidikan dan administrasi wakaf. Mereka juga mensponsori sekolah Al-Qur'an yang di dalamnya diajarkan aritmatika, geografi, sejarah dan bahasa Perancis. Tahun 1907 mereka mengekspresikan aspirasi politik dengan membuat jurnal The Tunisian. 


\section{Hubungan Afrika Utara dengan Andalusia}

Para penguasa muslim tidak melakukan Islamisasi secara sempurna. Mereka sudah puas dengan hanya menagih upeti dari kerajaan Kristen takhlukannya dan membiarkan mereka mempertahankan hukum dan adat, termasuk posisi hirarki tradisional (Yatim, 2004, p. 107). Periode penakhlukan kembali Spanyol (reconquista) dimulai sejak jatuhnya Kekhalifahan Umayyah abad ke-11. Andai kaum muslimin pada abad ke-8 menghancurkan sisa-sisa kekuatan Kristen di wilayah pegunungan Utara, mungkin kisah Spanyol selanjutnya akan berbeda. Paruh kedua abad ke-13, berlangsung proses Kristenisasi dan penggabungan Spanyol (Hitti, 2002, pp. 700-701). Akhir abad ke-13 di seluruh daratan, banyak kaum muslimin yang telah tunduk pada Kristen baik melalui penakhlukan maupun perjanjian tetapi tetap mempertahankan hukum dan agamanya, mereka disebut Mudejar (Mudajjan: seseorang yang diperbolehkan [oleh penakhluk Kristen] untuk tetap menghuni tempatnya dengan syarat membayar upeti).

\section{PENUTUP}

Sebelum Islam masuk ke Afrika Utara, daerah tersebut dikuasai oleh kekaisaran Romawi yang kejam. Bermacam-macam pungutan pajak dibebankan kepada masyarakat mulai dari pajak jiwa, pakaian, perabot rumah tangga, bahkan pajak orang mati. Semenjak kedatangan Islam orang Barbar terakomodasi dalam pemerintahan. keberadaan Islam telah menggoreskan tinta emas di wilayah tersebut dengan capaian peradaban yang tinggi. Keberadaan Islam di Afrika Utara mengalami masa yang berbeda-beda, mulai dari kejayaan hingga keterpurukan. Akhirnya pada abad ke-18 merupakan periode krisis bagi muslim Afrika Utara. Pemerintahan Usmani tidak mampu melindungi, sehingga perekonomian jatuh ke dalam perbudakan bangsa Eropa. Merosotnya kekuatan perekonomian turut berpengaruh dalam bidang pemerintahan sehingga mereka ditaklukkan oleh Perancis.

\section{REFERENSI}

Al-Ilm, D. (2013). Atlas Sejarah Islam: Sejak Masa Permulaan hingga Kejayaan Islam. Jakarta: Kaysa Media.

Amarullah, H. A. M. K. (1975). Sejarah Ummat Islam (Cetakan Ke). Jakarta: Bulan Bintang.

Bosworth, G. E. (1993). Dinasti-Dinasti Islam diterjemahkan dari The Islamic Dynasties oleh Ilyas Hasan. Bandung: Mizan.

Dunn, R. E. (2013). Petualangan Ibnu Battuta Seorang Musafir Muslim Abad ke-14. Jakarta: Yayasan Obor Indonesia.

Hitti, P. K. (2002). History of The Arabs. (R. C. L. Y. \& D. S. Riyadi, Trans.). Jakarta: PT Serambi Ilmu Semesta.

Islam, D. R. E. (1993). Ensiklopedi Islam (Vol. I, II \& II). Jakarta: PT. Intermesa.

Lapidus, I. M. (200o). Sejarah Sosial Ummat Islam. (G. A. Mas'adi, Trans.). Jakarta: PT RajaGrafindo Persada.

Maryam, S. (2012). Sejarah Peradaban Islam dari Masa Klasik hingga Modern (Cetakan Ke). Yogyakarta: LESFI. 
Vita Ery Oktaviyani

Sunanto, M. (2005). Sejarah Peradaban Islam. Jakarta: Rajawali Press.

Yatim, B. (2004). Sejarah Peradaban Islam: Dirasah Islamiyah II. Jakarta: PT RajaGrafindo Persada. 